\title{
STUDENTS' PERCEPTION OF TEACHER'S ROLE IN ONLINE LEARNING ENVIRONMENT WITHIN THE CONTEXT OF COVID -19
}

\author{
Larisa Lutskovskaia \\ Asst. Prof. Ph.D., RUDN University, Russia, laravas@list.ru
}

\begin{abstract}
The Covid-19 pandemic which quickly spread all over the globe has affected almost all spheres of social life including higher education posing significant challenges. Within short period of time both teachers and students had to switch from traditional format of teaching into online mode exclusively. Though leading universities of Russia have made some progress in introducing digital learning environment before the pandemic, still the majority of teachers were unprepared to design learning material suitable for online teaching, conduct teaching itself and monitor learning outcomes only through the medium on various internet platforms, which necessarily entails changes in teaching behaviour of the academia. All the factors mentioned above stipulate the relevance of the research. The article aims to investigate students' perception of changes in teacher's role caused by urgent shift into online learning environment. To achieve the set goal the author intends to solve the following task:
\end{abstract}

- To review the relevant research literature;

- To develop a questionnaire and conduct the survey of students' opinion with regard to changes in the teacher's role;

- To formulate recommendations based on the obtained data to enhance teaching outcomes.

The research methodology rests on method of survey including both qualitative and quantitative analysis. The survey involved second and third-year students at the Law Institute, RUDN University. The research findings revealed that most students perceive that there are changes in the teacher's role in pandemic era in comparison to traditional face-to face teaching towards greater detachment. The analysis of the obtained results enabled to identify the following areas where students would prefer to have more guidance on teacher's part: social interaction, learning content, technical issues.

Keywords: Covid-19, online teaching, online learning environment, teacher's role

\section{INTRODUCTION}

International crisis caused by Covid-19 pandemic has had repercussion almost in all spheres of social life including the sphere of higher education. Despite the fact that many leading institutions of higher education both in Russia and worldwide have made significant achievements in creating digital learning environment, still the overwhelming majority of academia proved to be unprepared to total shift from traditional face-to-face teaching model to online teaching over a short period of time and under pressing circumstances as well. As many researchers point out, a modern university teacher who is already saddled with sufficient amount of 
workload that apart from teaching also involves research, exasperating variety of paperwork etc. (Houston, Meyer and Paewai 2006, Rapanta et al. 2020), is experiencing additional stress caused by technical as well as pedagogical challenges associated with teaching in distant format exclusively.

Due to the emergency of the Covid-19 situation the majority of university teachers who belong to various age groups have not been provided with specific training in technological issues of online teaching at all, or have been rather superficially briefed into the technical capabilities of the Internet platforms used by a specific university, such as MS Teams or Zoom that are most frequently used by universities in Russia. Nor they are provided with adequate technical support by university IT specialists. As the result teachers increasingly feel left alone to struggle with technology difficulties and enhance their IT competences.

The development of teaching materials suitable for online teaching as well as organizing and maintaining the workflow in distant format presents another significant challenge to deal with for teachers with no or little previous experience in online teaching. Effective online teaching requires specific skills in developing teaching materials, its presentation via ITC means, eliciting learners' feedback and enhancing learners' motivation etc. Such skills involve many pedagogical, technical as well as psychological aspects in which university teachers are provided with little guidance and instruction.

All the above factors contribute to higher degree of uncertainty in teaching behaviour; teachers virtually have to grope their way in struggling to ensure effective online teaching. This uncertainty is projected at students' perception of online learning generally and of teacher's role in particular.

The article aims to analyse students' perception of teacher's role within the context of urgent shift to online learning through the survey experiment, identify their learning needs and on the basis of the empirical data formulate recommendations that would contribute to enhancement of online teaching efficiency.

We set the following tasks to achieve the research goal:

- To review the relevant research literature to provide sufficient background for the discussed problematic field;

- To develop a questionnaire to elicit students' opinion on teacher's role in online classes;

- To analyse the obtained data with the view of identifying the problematic areas as perceived by the students;

- To formulate recommendations that would contribute to enhancement of online teaching efficiency through identification of particular learning needs.

\section{LITERATURE REVIEW}

Dramatic situation with Covid-19 has prompted the researchers to investigate various aspects of its influence on education generally and on higher education in particular. Forced movement of education into digital environment is one of the central issues investigated by researchers (Jandrić, 2020). The urgent shift from face-to face teaching model towards the remote teaching which necessarily entails the issues of teachers' ICT competence as well as their psychological and pedagogical preparedness is given special emphasis by many scholars (Espino-Diaz et all, 2020). Remote teaching requires certain pedagogical content knowledge which basically involves developing learning materials appropriate for digital learning environment as well as organizing effective teaching and learning through the use of ICT. These issues are also focused on in recent researches (Rapanta et al. 2020).

The regional impact of the pandemic crisis on education and its implications for particular educational institutions is also given attention by scholars. For instance, Allen, Rowan \& Singh point out that though there is a universal trend towards remote teaching and learning, but its impact on academia and students greatly vary depending on university's general level of development of digital learning environment. (Allen, Rowan \& Singh, 2020).

The impact of Covid-19 pandemic is analysed the scholars from institutional perspective as well. Thus A. Atabekova investigates the issue of communication between the institutions of higher education and various stakeholders within the context of the pandemic prevention measures, special emphasis is laid on the role of the University (Atabekova, 2020).

\section{RESEARCH METHODOLOGY}

The research methodology is based on method of survey, the obtained data were subjected to quantitative and qualitative analysis. The survey participants were second and third-year students at Law Institute. The 
total number of the participants who volunteered to take part in the survey was 70 .

The questionnaire developed by the author contained the following questions:

1) Do you prefer on-line learning or traditional face-to-face learning in class, specify why?

2) What factors do you think contribute to making online learning successful?

3) Do you identify any changes in teacher's role in online lessons in comparison to traditional lessons?

The questionnaire was sent to the volunteers via corporate e-mails. All 70 questionnaires were received back by the author with students' responses. All the questions offered to students are open ones, and designed to elicit comprehensive responses, students were also strongly encouraged to provide their comments. However, students did not have to provide answers for all questions, they could choose to share their opinion on issues that seemed most important for them.

\section{ANALYSIS AND DISCUSSION}

Answering the first questions of the survey : "Do you prefer on-line learning or traditional face-to-face learning in class, specify why?" students tended to provide quite definite answers in terms of "yes/no/ I don't know". Percentagewise the responses obtained can be presented in a diagram as follows:

Fig. 1 Students' responses

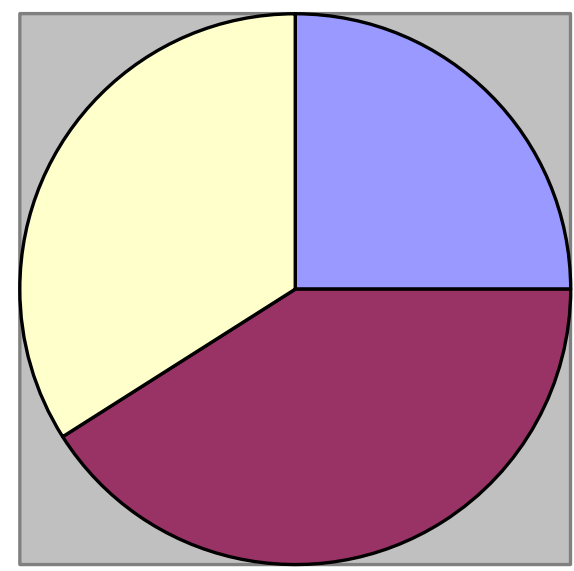

口Yes $\mathbf{2 5 \%}$

№ $41 \%$

口I hasitate to answer $34 \%$

As is evident from the diagram above only $25 \%$ of students could definitely state that they were satisfied with remote learning, far bigger per cent of students would prefer to return to traditional form of learning. Surprisingly enough the survey results clearly indicate that there is rather high per cent of those students who had no definite opinion on the preferred mode of learning. Among the advantages listed in the commentaries the most obvious one is the convenience of working from home, including other cities, towns and even countries. However, the majority of students point out psychological difficulties of learning in remote regime. Among such difficulties they identify psychological detachment from both teacher and group mates, communication takes longer, the immediate reaction of the participants of communication is unclear since the majority of groups work with their cameras off, which creates the effect of emotional suspense.

Another aspect mentioned by the students (about 29\% of the respondents) in the commentaries is the difficulties related to technology issues. It is interesting to note that students who negatively view the remote learning and students who "hesitate" rather often indicated in their comments that they expect a teacher to guide them through these difficulties. The author believes that this factor coupled with high per cent of negative answers indicates students' general unpreparedness to total online learning.

Answering the second question offered in the questionnaire students provided rather ample commentaries. Data obtained from students' responses suggest that among factors contributing to successful online learning students in the first place identify psychologically comfortable and learner-friendly atmosphere of online sessions $(87 \%$ of the respondents mentioned this factor this way or another). High per cent of the respondents believe that it is teacher's responsibility to create such atmosphere in the virtual class. Teacher is expected to help students overcome psychological barriers of digital environment. 
About $71 \%$ of the respondents responding the same question indicated that they value communication with the teacher as a significant factor contributing to successful online learning, and on the contrary just listening to prerecorded lectures or doing assignments with no possibility of discussing the material with the teacher makes the learning process depersonalized and less effective. Surprising small number of respondents $(24 \%$ of the respondents) mention specifically designed for online learning materials as a key factor of successful learning. Due to the urgency of the shift to online learning the majority of teachers continue using the teaching materials they had used before the pandemic with small or no adaptation to the online learning environment. The survey results obtained for the second question reveal that students tend to perceive a teacher as a central figure ensuring effectiveness of the overall learning process.

The data obtained for the third questionnaire item revealed that about $71 \%$ of students feel that teacher's role in online classes caused by Covid-19 pandemic has changed in comparison to pre-pandemic traditional face-to-face classes. The results of the quantitative procession of students' comments indicate that more than half of the respondents perceive that teacher's role shifted more towards online conferencelmeeting management. In the comments students involved in the experiment clearly indicate that teachers are more concerned with technical issues, for example, teachers constantly checking if they are doing everything correct to run the online meeting properly, press "the right button" to make the recording of the meeting or share the screen with students etc. Students perceive that the above-mentioned technical issues take up significant proportion of teacher's attention.

Respondents also point out the psychological detachment of the majority of teachers as a problem. The necessity to keep to the strict time limits of the online communication leaves less opportunity for discussing the material with a teacher. This becomes a problem for more shy students, who do not feel comfortable asking questions generally and especially so when the lesson is being recorded.

\section{CONCLUSION}

The conducted research made it possible to identify the problematic areas associated with teachers' role in the context of urgent move to online learning caused by Covid-19 pandemic through the prism of students' perception.

The obtained data revealed that students generally perceive the changes of teacher's role towards greater psychological detachment caused by time limits of online communication on the one hand and by teacher's concern with technical issues on the other.

On the basis of the experimentally obtained data it is possible to formulate some recommendations to mitigate the consequences of the urgent move to online teaching and learning:

- To ensure greater involvement of the institutions of higher education in providing not only technical support to teachers and students, but also in organizing constant developing of teachers' IT competences. Building confidence in IT competence is crucial for transferring the focus of teacher's attention from technical issues to actual "teaching".

- Since effective online learning and teaching largely depends on excellent communicative skills, we believe it would be useful to organize purpose-specific master classes to enhance teachers' communicative competence in digital environment.

The proposed measures are by no means exhaustive as online teaching generally and in pandemic crises period especially is a multy-faceted phenomenon with many variables that require further investigation. The results obtained in the cause of the experiment may find further application in designing materials and courses for online teaching.

\section{REFERENCE LIST}

Allen, J., Rowan, L., Singh P. (2020). Teaching and teacher education in the time of COVID-19. Asia-Pacific Journal of Teacher education, 48:3, 233-236.

Atabekova, A. (2020). University discourse to foster youth's sustainability in societyamidst COVID19: International and Russian Features. Sustainability, 12(18), 7336.

Espini-Díaz, L., Fernandez-Caminero, G., Hernandez-Lloret, C.M., Gonzales-Gonzales, H., Alvarez-Castillo J.L. (2020). Analyzing the Impact of COVID-19 on education professionals. Toward a paradigm shift: 
ICT and Neuroeducation as a binominal action. Sustainability, 12, 5646.

Houston D., Meyer, L.H., \& Paewai S. (2006). Academic staff workloads and job satisfaction: expectations and values in academe. Journal of Higher Education Policy and Management, 28(1), 17-30.

Jandrić, P. (2020). Postdigital research in the time of Covid-19. Postdigital Science and Education, 2(2), 233238.

Rapanta, Ch., Botturi, L., Goodyear, P., Guárdia, L. (2020). Online university teaching during and after Covid-19 crisis: refocusing teacher presence and learning activity. Postdigital Science and Education, 2:923-945. 